\title{
The current state of hospital-based emergency medicine in Germany
}

\author{
Tareg A. Bey • Sigrid A. Hahn • Heinzpeter Moecke
}

Received: 8 October 2008 / Accepted: 9 October 2008 / Published online: 19 November 2008

(C) Springer-Verlag London Ltd 2008

\begin{abstract}
Germany has a long tradition of having physicians, often anesthesiologists with additional training in emergency medicine, deliver prehospital emergency care. Hospital-based emergency medicine in Germany also differs significantly from the Anglo-American model, and until recently having separate emergency rooms for different departments was the norm. In the past decade, many hospitals have created "centralized emergency departments" [Zentrale Notaufnahme (ZNAs)]. There is ongoing debate about the training and certification of physicians working in the ZNAs and whether Germany will adopt a specialty board certification for emergency medicine.
\end{abstract}

Keywords International emergency medicine · Germany · Zentrale Notaufnahme

The views expressed in this paper are those of the author(s) and not those of the editors, editorial board or publisher.

\section{T. A. Bey}

Department of Emergency Medicine,

University of California Irvine, UCI Medical Center,

101 The City Drive, Rte 128,

Orange, CA 92868, USA

\section{S. A. Hahn $(\bowtie)$}

Department of Emergency Medicine,

Mount Sinai School of Medicine,

1 Gustave Levy Place,

New York, NY 10029, USA

e-mail: sigridahahn@gmail.com

e-mail: sigrid.hahn@mssm.edu

\section{H. Moecke}

Asklepios Kliniken Verwaltungsgesellschaft mbh,

3. Asklepios Kliniken Germany, Konzernbereich Medizin \&

Wissenschaft, c/o AK St. Georg Haus P, Lohmuehlenstrasse 5, 20099 Hamburg, Germany

\section{Introduction}

In September 2008, the European Society of Emergency Medicine (EuSEM) held their 5th Congress of Emergency Medicine in Munich, Germany. Cosponsored by the recently founded German Society for Interdisciplinary Emergency Medicine [Deutsche Gesellschaft Interdisziplinäre Notfallaufnahme (DGINA)], the conference featured sessions ranging from emergency medicine (EM) education and the "core curriculum" to emergency department design and operations [1]. Despite ongoing debate about residency training and the need for specialty board certification for EM in Germany, it was evident at the meeting that the discussion is expanding from the well-developed prehospital emergency medical services (EMS) system towards the establishment of integrated, multidisciplinary emergency departments. This article will review the background and current state of EM in Germany and discuss some of the current controversies.

\section{Background of EM in Germany}

Germany (Fig. 1) has a long tradition of having physicians deliver prehospital emergency care, and traditionally the terms "emergency physician" (Notarzt) and "emergency medicine" (Notfallmedizin) have referred exclusively to the prehospital setting [2]. Germany has a two-tiered system with basic life support and advanced life support (ALS) units staffed by emergency medical technicians (EMTs) or paramedics. Each state governs its own EMS system, and most have implemented a "rendezvous system," where a physician and paramedic travel to the prehospital call in a car, independently of the ALS units [3, 4]. EMS physicians are often anesthesiologists, but also include surgeons and 


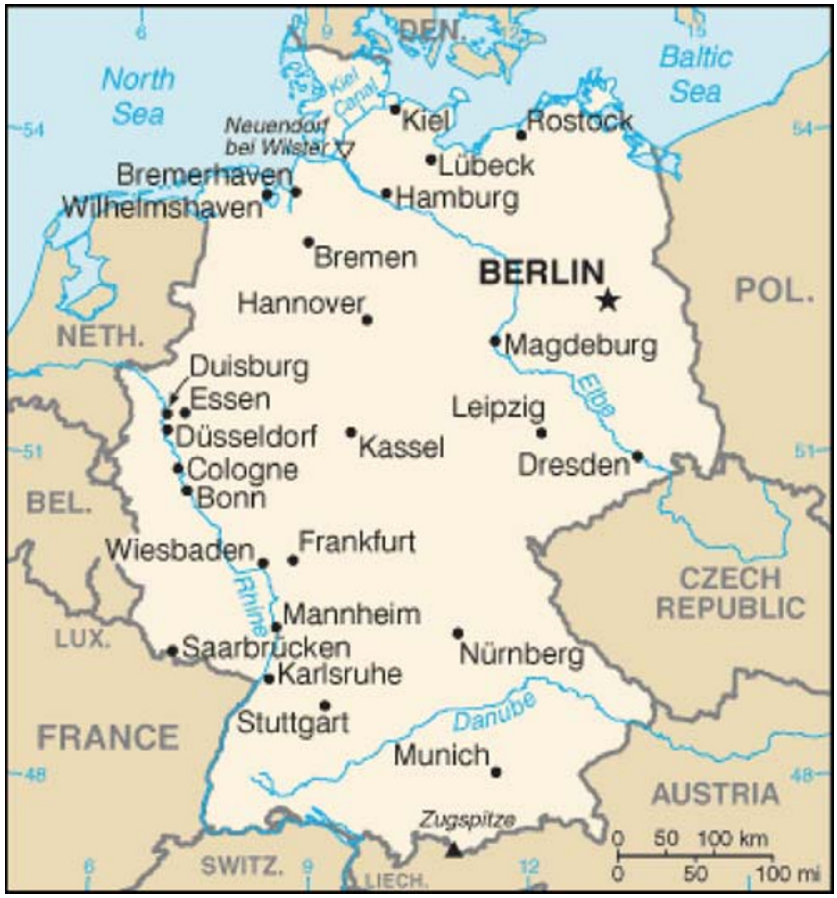

Fig. 1 Map of Germany, population 82,369,522 (July 2008 est.), main language spoken German. Map and information from Central Intelligence Agency World Factbook (https://www.cia.gov/library/ publications/the-world-factbook/geos/gm.html)

internists. It is currently a federal mandate that a physician supervise invasive procedures in the field. Nevertheless, critics in Germany voice concerns over quality assurance in prehospital medical care, in part because there are no wellestablished protocols or online medical controls for EMTs and paramedics. Physicians must complete the requirements for "supraspecialty" training in EM for prehospital work, as described in detail below.

Hospital-based EM in Germany differs significantly from the Anglo-American model. Historically, there have been separately staffed "emergency admission areas" (Notfallaufnahme, here forth referred to as "emergency rooms") within individual hospitals for internal medicine, surgery, trauma, gynecology and obstetrics, pediatrics, and in larger teaching hospitals, there are often additional emergency rooms for ophthalmology and otolaryngology, among others [5-7]. A potential advantage of these singlediscipline emergency rooms is the relative ease with which patient care is transferred to the inpatient team. However, the staff physicians working in these emergency rooms are often still in training (i.e., in residency), have not necessarily been specifically trained in emergency care, and sometimes work without attending supervision. In the past decade, many hospitals have created "centralized emergency departments" [Zentrale Notaufnahme (ZNAs)], as discussed below. These ZNAs are usually staffed by internists, surgeons, anesthesiologists, and other specialists as well as physicians in training.

The demand for hospital-based emergency care is expected to increase in the near future. Germany has a statutory health insurance system, which covers approximately $88 \%$ of the population, with private insurance covering almost everyone else [5]. As of 2007, the German Federal Statistical Office reported that only $0.3 \%$ of the total population had no health care coverage [8]. With relatively easy and affordable access to office-based physicians, as well as 24-h house call service by officebased physicians, emergency rooms and ZNAs had not been a major source of health care in Germany. However, rising health care costs have triggered cost-containment measures, and office-based medicine has become less financially attractive for physicians due to frozen or scaled back reimbursement schedules. There is a trend among German physicians to choose better paying specialties, and it is estimated that there will be a shortage of 15,000 primary care physicians in Germany within the next 15 years [9]. Many patients, especially in rural areas and the former East Germany, will have very limited or no access to primary care. As has been observed in the USA [10], poor access to primary care is expected to translate into higher patient volumes in the emergency rooms. Additional pressure is being imposed on emergency rooms as a result of hospital closures, which are occurring due to decreased reimbursements secondary to a cap of annual spending on health care and the introduction of diagnosisrelated groups (DRG). Major reasons for increased overhead for hospitals are rising energy prices, increases in staff salaries, and rising cost of care due to the higher morbidity of chronically ill patients.

\section{Professional organizations for EM}

There are two large German EM professional organizations. The German Association of Emergency Physicians [Bundesvereinigung der Arbeitsgemeinschaften der Notärzte Deutschlands (BAND)] is an umbrella organization for state emergency physician organizations. BAND's primary goal has been to improve prehospital care in Germany, work towards the establishment of uniform training requirements for physicians nationwide, and to advocate for the interests of emergency physicians [11]. BAND also cohosted a conference in 2005 where representatives from related political and professional organizations gathered to discuss the future of the ZNA and hospital-based EM [12]. The other large organization, the German Interdisciplinary Association of Critical Care Medicine [Deutsche Interdisziplinäre Vereinigung für Intensiv- und Notfallmedizin (DIVI)], is an association of many medical professional 
organizations and interest groups that focuses on promoting practice and research in the fields of intensive care medicine and EM [13]. Additionally, DIVI promotes research and quality improvement in prehospital care, transport of critically ill patients, and disaster medicine. Very recently DIVI has changed its structure and has become a member organization. In addition, several smaller groups that promote inhospital EM have been established. In 2004, the Bundesarbeitsgemeinschaft ZNA was founded as an independent "think tank," and the aforementioned DGINA was established in 2006.

\section{The emergence of the "centralized emergency department" (ZNA)}

Economic pressure, as well as a changing medical and political environment, has encouraged numerous German hospitals to introduce ZNAs. The goal is to consolidate services, thereby promoting higher quality care, customer satisfaction, and cost-effectiveness. A majority of ZNAs report to the department of internal medicine or surgery, but a few ZNAs have financial autonomy and report directly to the medical director, $\mathrm{CEO}$, or CFO of the hospital. An example of a new ZNA is found in the 955-bed tertiary care hospital, Munich-Bogenhausen, which combined the medical and surgical emergency rooms into a single, integrated department with the mission to care for all emergency patients as well as patients who present with more routine problems [14]. In addition to a resuscitation bay, they have a six-bed "acute care" area, which has intensive care capabilities, and additional zones for "intermediate care" and observation. In the past, critically ill patients would have been admitted directly to the intensive care unit (ICU), but in this new ZNA patients are now stabilized in the acute and intermediate care areas prior to being admitted to the hospital. In some cases, this allows patients to be stabilized and admitted to a non-ICU setting, using resources more appropriately and keeping ICU beds available for more critically ill patients. Furthermore, this system allows an emergency physician based in the Munich-Bogenhausen hospital to attend emergencies in the field and then continue caring for the patients when they arrive back in the ZNA.

\section{EM education, training, and certification}

Currently, EM is considered a "supraspecialty," and the training requirements for becoming a licensed prehospital EM provider include a minimum of 24 months of residency in anesthesia, surgery, internal medicine, or pediatrics. At least 6 of 24 of these months must be spent rotating in anesthesiology, the ICU, or an emergency room. The trainee also must attend an 80-h course covering various aspects of EM, as specified by each State Medical Association. The final requirement is a Praktikum, or internship, under the supervision of a prehospital physician, which includes at least 50 ambulance calls [2]. However, the complexity of cases and treatment options seen in a ZNA are considerably broader than in the prehospital environment, and therefore "supraspecialty" certification is considered by some to be inadequate for inhospital ZNA work [15].

EuSEM has defined the practice of EM as encompassing prehospital and inhospital triage, resuscitation, initial assessment, and management of undifferentiated urgent and emergency cases. Based on this, a curriculum task force developed an internationally recognized core curriculum for EM [16]. They outlined a 5-year training schedule, including a minimum of 3 years to be spent purely in emergency department-based training, with varying exposure to other specialties, depending on the scope of practice expected in that country. Core competencies (see Table 1), knowledge, and skills were identified which cover clinical aspects of EM, as well as other relevant topics, such as the development of prehospital and inhospital emergency medical systems.

DGINA has also developed a core curriculum and training requirements for EM residency in Germany, derived from the EuSEM document [17]. The proposed training is 60 months long, with at least 36 months in a ZNA and 6 months of ICU or anesthesiology. Up to 18 months of training can be in surgery or internal medicine, but this is optional and this time can also be done in a ZNA. The resident must also complete an 80 -h course on EM and participate in 50 prehospital emergency calls. The proposal also enumerates the content and skills that the physician must possess upon completion of training. The concept of specialty certification in EM remains controversial within the German medical community.

\section{Recognition of hospital-based EM as a specialty}

EuSEM has published a policy statement that calls for the recognition of EM as a primary medical specialty

Table 1 Core competencies in EuSEM's emergency medicine curriculum

\footnotetext{
1. Patient care

2. Medical knowledge and clinical skills

3. Communication, collaboration, and interpersonal skills

4. Professionalism and other ethical and legal issues

5. Organizational planning and service management skills

6. Education and research
} 
[18]. Currently, however, 16 of 27 European countries, including Germany, do not recognize the specialty [15]. The German Medical Council [Bundesärztekammer (BÄK)] is the federal association of all public State Medical Chambers. The BÄK oversees the development of standards for medical specialties, and any changes, including the establishment of new specialties, must be approved by the "Parliament of German Physicians" (Deutscher Ärztetag). In 2007, a proposal by Moecke and Lackner was submitted to the BÄK outlining suggested responsibilities of the ZNA and inhospital emergency physicians (Empfehlung der Bundesärztekammer zur Qualifikation von Ärztinnen und Ärzten in Zentralen Notaufnahmen, personal communication). These include caring for emergency cases, establishing a preliminary diagnosis, determining patient dispositions, treating and releasing stable patients, and the consultation of experts as needed. In 2008, DGINA proposed to the BÄK that EM become its own specialty. They emphasized the medical and medicolegal risks associated with not having an independent specialty in EM.

\section{Controversies}

Although ZNAs are gaining acceptance, there is still disagreement about which physicians should be staffing and running these departments. There is still considerable controversy within the German medical establishment regarding the development of EM as an independent medical specialty [6]. The German Society of Surgery and the German Society of Internal Medicine published a joint statement in which they argue that the introduction of hospital-based emergency physicians are neither necessary nor cost-effective [19]. The statement acknowledges that the administration of the ZNA should be assumed by a single department, but proposes that the directorship should be by the medical specialty which oversees the majority of patients in the ZNA (i.e., internal medicine or surgery). A rotating system of leadership was proposed, alternating between internal medicine and surgery every 2-3 years.

A potential obstacle to board certification in EM is the cost of training prehospital and inhospital emergency physicians. It is considered unlikely that the prehospital physician model will be revised or abandoned in the near future. However, with an increasing need for emergency care in Germany, prehospital and hospital-based practices will need to be better integrated and more efficient in the future, necessitating that the training programs and career paths for all emergency physicians be more clearly defined.

\section{Conclusions}

In Germany, inhospital EM is changing, with an increasing number of hospitals opening ZNAs. However, there is still considerable variability across the country. Furthermore, there is an ongoing controversy about the necessary training and qualifications for physicians working in the ZNA.

Conflict of interest None.

\section{References}

1. European Society of Emergency Medicine homepage. Available from: http://www.eusem2008.org. Accessed 3 Oct 2008

2. Moecke H (1998) Emergency medicine in Germany. Ann Emerg Med 31(1):111-115

3. Grüne F, Prokop A, Blomeyer R et al (2001) Zentrale Notfallaufnahme des Universitätsklinikums Köln im Verbund des städtischen Rettungswesens. Notfall Rettungsmed 4(6):449-460

4. Härtel D, Christel E, Brockmeier J et al (2007) Verbesserung der Behandlung von Patienten mit akutem Koronarsyndrom durch Aufbau einer Netzwerkstruktur im ländlichen Raum. Notfall Rettungsmed 10:423-431

5. Platz E, Bey T, Walter FG (2003) International report: current state and development of health insurance and emergency medicine in Germany. The influence of health insurance laws on the practice of emergency medicine in a European country. J Emerg Med 25(2):203-210

6. American College of Emergency Physicians: International Ambassador Reports. Available from: http://www.acep.org/ ACEPmembership.aspx $? i d=31034$. Accessed 3 Oct 2008

7. Bey T (2007) Schnittstelle Zentrale Notaufnahme. Entwicklung der Emergency Medicine in den USA, Bedeutung der Emergency Departments für das amerikanische Gesundheitssystem sowie Entwicklung der Zentralen Notaufnahmen in Deutschland. Notfall Rettungsmed 10(5):323-324

8. Statistisches Bundesamt Deutschland. Available from: http://www. destatis.de/jetspeed/portal/cms/Sites/destatis/Internet/DE/Presse/ pm/2008/02/PD08 045 122.psml. Accessed 4 Oct 2008

9. Korzilius H (2008) Hausärztemangel in Deutschland: Die grosse Landflucht. Dtsch Aerztebl 105:A-373-A-374

10. Committee on the Future of Emergency Care in the United States Health System, Institute of Medicine of the National Academies (2007) Hospital-based emergency medicine: at the breaking point. National Academies Press, Washington, DC

11. Bundesvereinigung der Arbeitsgemeinschaften der Notärzte Deutschlands. Available from: http://www.band-online.de/. Accessed 4 Oct 2008

12. Schlechtriemen T, Dirks B, Lackner C et al (2005) Die „Interdisziplinäre Notaufnahme“ im Zentrum zukünftiger Notfallmedizin. Notfall Rettungsmed 8(7):502-511

13. Deutsche Interdisziplinäre Vereinigung für Intensiv- und Notfallmedizin(German Interdisciplinary Association of Critical Care Medicine). Available from: http://www.divi-org.de/Startseite.25.0. html. Accessed 2 Oct 2008

14. Koeniger R, Räwer H, Widmer R et al (2006) Präklinik mit integrierter Aufnahmestation: Zukunftsweisendes Konzept. Dtsch Aerztebl 103:A-2770-A-2773

15. Fleischmann T (2007) Facharzt fuer Notfallmedizin: Unverzichtbar auch für Deutschland. Notfall Intensivmed 1:22 
16. EuSEM Task Force on Curriculum. European Curriculum for Emergency Medicine. 2008. Available from: http://www.eusem. org/downloads/pdfs/Emergency_Medicine_curruculum_final_ draft.pdf. Accessed 2 Oct 2008

17. Deutsche Gesellschaft Interdisziplinäre Notfallaufnahme. Erste revision: Weiterbildungscurriculum zum Facharzt für die Notfallmedizin. 2007. Available from: http://www.dgina.de/pages/posts/ 12.02.2007-erste-revision-weiterbildungscurriculum-zum-facharztfuer-die-notfallmedizin5.php?p=10. Accessed 2 Oct 2008

18. European Society of Emergency Medicine. Policy Statement on Emergency Medicine in Europe. 2007. http://www.eusem.org/ Pages/About_EuSEM/Policy_Statements/Policy_Statements.html. Accessed 2 Oct 2008

19. Deutsche Gesellschaft für Innere Medizin, Deutschen Gesellschaft für Chirurgie. Zur Problematik Zentraler Notaufnahmen. Gemeinsame Stellungnahme der Deutschen Gesellschaft für Chirurgie und der Deutschen Gesellschaft für Innere Medizin. 2006. Available from: http://www.dgch.de/downloads/dgch/Aktuelles/ ZentrNotaufnahme_DGCH-DGIM_Vs_17_10_06.pdf. Accessed 5 Oct 2008

Tareg Bey is Clinical Professor of Emergency Medicine and Director of International Emergency Medicine at the University of California
Irvine. He is board certified in emergency medicine and medical toxicology in the USA and in anesthesia and critical care in Europe. $\mathrm{He}$ is the ACEP Ambassador to Germany.

Sigrid Hahn is Assistant Professor of Emergency Medicine and the Associate Director of the Global Health Center at the Mount Sinai School of Medicine in New York. She is a member of the American College of Emergency Physician's Clinical Policy Committee and a board member of the International Journal of Emergency Medicine.

Heinzpeter Moecke is board certified in anesthesiology with a strong background in intensive care and prehospital emergency medicine. He has served as Chief Medical Officer for the Hamburg State Fire Department and as Head of the Department of Anesthesiology and Critical Care at two city hospitals in Hamburg. He is the Medical Director at Asklepios Klinik Nord in Hamburg, Germany. He founded the Institute for Emergency Medicine within the hospital group. The institute offers different training modules for EMS workers and is a certified international training institution of the American Heart Association (AHA). 